\title{
Reports
}

\section{Diffusion of Antimony into Silicon Epitaxial Layers from Buried Layers}

\author{
Sho NaKanuma and Sokichi Yamagishi \\ Integrated Circuits Division, Nippon Electric Company, Ltd. \\ Kawasaki, Japan
}

Received Nov. 20, 1967

\begin{abstract}
Diffusion of antimony into silicon epitaxial layers from "buried" layers in the junction isolated integrated-circuits has been investigated as a function of temperature and surface concentration, where the diffusion occurs according to the complementary error function from a finite layer. The diffusion coefficient of antimony in silicon was given by $D=3.63 \times 10^{2} \exp (-101400 / \mathrm{RT}) \mathrm{cm}^{2} / \mathrm{sec}$ and this was compared with those published in literatures.
\end{abstract}

\section{Introduction}

Antimony has been widely used as a diffusant for the formation of "buried" layers in integrated circuits, because of its low diffusion coefficient and of low autodoping during epitaxial growth. The diffusion of antimony in silicon was first studied by Dunlap, et al. ${ }^{1)}$ and then Fuller, et al. ${ }^{2)}$ in sealed quartz tubes with $\mathrm{Sb}_{2} \mathrm{O}_{3}$ as a diffusant. An experiment on diffusion of antimony by using radioactive $\mathrm{Sb}^{124}$ was reported by Rohan, et al. ${ }^{3}$ ) Thurston, ${ }^{4}$ ) et al. studied it as a function of surface concentration in a closed system. Recently, a liquid antimony diffusion system using antimony ethoxide as a diffusant was developed by Gittler ${ }^{5}$.

There has been a considerably large disagreement among the diffusion coefficents in these literatures. This is in part due to the uncertainty of surface concentrations and in part to the difference in diffusion process. In addition, these diffusion coefficients seems to be not always valid for the diffusion from "buried" layers into epitaxial layers. If no interfacial region with a high diffusion coefficient exists between epitaxial layer and "buried" layer, diffusion coefficients measured in this paper would be more reliable and applicable to the fabrication of integrated circuits than those obtained by conventional methods.

The initial step for the fabrication of "buried" layers, which reduce series resistance in collector regions of transistors and diodes, is to oxidize a substrate so as to be able to form window which will define areas for the diffusion of antimony. After the diffusion and removal of oxide 
mask, an $n$-type epitaxial layer is deposited over the substrate with "buried" layers of antimony. Then transistors and diodes are fabricated in the epitaxial layers just above the "buried" layer by successive diffusion processes. The problems in the antimony diffusion are surface damage and reproducibility in obtaining a definite sheet resistivity and surface concentration. Surface damages deteriorate the electrical characteristics of devices, and the redistribution of antimony into epitaxial layers during the fabrication of integrated circuits, particularly, an isolation diffusion at $1200 \sim 1250^{\circ} \mathrm{C}$ for several hours for junction isolated integrated circuits, influences the series resistance of transistors.

There have been neither data on diffusion coefficients of antimony into silicon epitaxial layers from "buried" layers nor on the surface concentrations in such a diffusion process so far. Therefore, it is important to obtain them for the design as well as the fabrication of integrated circuits from the engineer's point of view.

\section{Experimental Procedures}

All the diffusion runs were carried out in an open tube and two zone gas flow system, and the diffusion process consists of two steps; one is the predeposition of antimony from a source of $\mathrm{Sb}_{2} \mathrm{O}_{3}$ for $1 \sim 2.5 \mathrm{hrs}$ in nitrogen containing a small amount of oxygen to prevent thermal etching of substrates, where the temperatures of source and predeposition were $580^{\circ}$ and $1230^{\circ} \mathrm{C}$, respectively, and the other is a drive-in diffusion at $1230^{\circ} \mathrm{C}$ in nitrogen or oxygen. Substrates were cut at $90^{\circ}$ to the $\langle 111\rangle$ axis from boron doped $\mathrm{CZ}$ crystals with two different doping leveis of $4.4 \times 10^{14}$ and $3.4 \times 10^{15}$ atoms/cc, and chemically or mechanically polished.

For the determination of diffusion coefficients in the redistribution process from the "buried" layers into $p$-type epitaxial layers, differential sheet conductance and $p$ - $n$ junction methods were used.

Depositions of the $p$-type epitaxial layers containing boron of $5.5 \times 10^{16}$ and $3.4 \times 10^{15}$ atoms/cc were done at $1185^{\circ} \mathrm{C}$ by the hydrogen reduction of $\mathrm{SiC}_{4}$ doped with $\mathrm{B}_{2} \mathrm{H}_{6}$, followed by the heat treatments in nitrogen in the temperature range $1150 \sim 1255^{\circ} \mathrm{C}$. Before and after the heat treatment the diffused junctions in the epitaxial wafers are revealed by angle lapping and staining method.

Impurity profiles in the substrates and epitaxial layers were determined by the differential conductance method; that is, the sheet conductance changes after each removal of thin layers by chemical etching according to the equation,

$$
\rho^{-1}(\mathrm{x})=\frac{\mathrm{d} \sigma(\mathrm{x})}{\mathrm{dx}},
$$

where $\rho(\mathrm{x}), \sigma(\mathrm{x})$ and $\mathrm{x}$ denote the resistivity, the sheet conductance and the distance from the surface, respectively. Impurity concentrations were calculated using the curves of impurity concentration versus resistivity proposed by Irvin ${ }^{6}$.

In order to improve the accuracy of measurements, the diffusion length is calculated by the following equation.

$$
\mathrm{x}_{\mathrm{e}}=\frac{\left(p_{\mathrm{o}}-p+\mathrm{x}_{\mathrm{eo}}\right)+\left(n-n_{\mathrm{o}}+\mathrm{x}_{\mathrm{eo}}-\Delta \mathrm{x}_{\mathrm{s}}\right)}{2}
$$

where $\mathrm{x}_{\mathrm{e}}$ is the diffusion length during heat treatment and epitaxial growth, $x_{\mathrm{e}_{\mathrm{o}}}$ is the diffusion length during epitaxial growth, $p_{0}$ and $p$ are the junction depths before and after the heat treatment in the epitaxial layer, $n_{0}$ and $n$ are the widths of $n$ layer before and after the heat treatment, respectively, $\Delta \mathrm{x}_{\mathrm{s}}$ is the moved length of the $p-n$ junction in the substrate during the heat treatment, and $t$ is the thickness of epitaxial layer. This is shown 


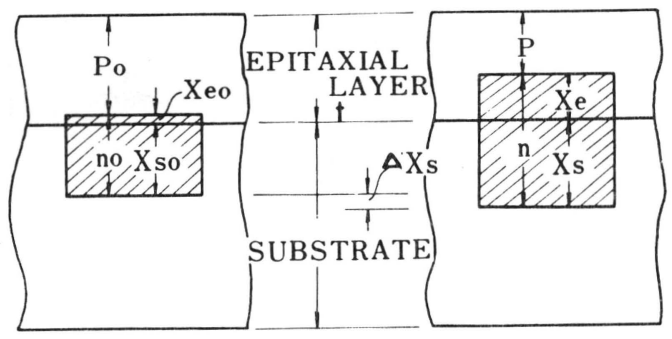

BEFORE HEAT

TREATMENT
AFTER HEAT

TREATMENT
Fig. 1 Cross section of "buried" layer before and after heat treatment

in Fig. 1 and shaded areas are "buried" layers. If $t$ is constant, $\mathrm{x}_{\mathrm{e}}$ could be simply expressed by the equation,

$$
\mathrm{x}_{\mathrm{e}}=\mathrm{p}_{\mathrm{o}}-\mathrm{p}+\mathrm{x}_{\mathrm{eo}},
$$

but this does not give a satisfactory result, because of impossibility in obtaining the $p-n$ junction depth before and after heat treatment at the same position in one wafer and the errors in measuring thickness. Use of averages of $p_{\mathrm{o}}$ and $n_{\mathrm{o}}$ at several points on each wafer and of $\Delta x_{s}$ among several wafers on the determination of $x_{e}$ for the equation (2) could give more reliable results than use of the equation (3). So each wafer was chipped to 8 piecens of which were used for the measurement of $n_{0}$ and $p_{0}$, and the rest of them were utilized for that of $n$ and $p$. The averages of $\Delta \mathrm{x}_{\mathrm{s}}$ among 6 wafers were used. As $\mathrm{x}_{\mathrm{eo}}$ calculated by diffusion coefficients and surface concentrations was an order of $0.5 \sim 0.6$ microns, the errors of $\mathrm{x}_{\mathrm{eo}}$ may not be significant for the determination of $x_{e}$.

Surface concentrations after the predeposition and the drive-in diffusion of antimony were also determined by an infrared plasma resonance $\operatorname{method}^{7)}$ in the wave length range 13 22 microns.

\section{Experimental Results}

Surface concentrations measured by the differential conductance and the plasma resonance method, and diffusion length after the drive-in diffusion for $7 \mathrm{hrs}$ in oxygen are listed in Table 1, representing straight line approximation of surface concentration versus sheet resistivity.

Table 2 is the surface concentrations obtained by the plasma resonance method during drive-in diffusion at $1230^{\circ} \mathrm{C}$ for 12 hrs and Fig. 2 shows some impurity profiles in substrates after the drive-in diffusion.

Fig. 3, Fig. 4 and Fig. 5 show the diffusion length after heat treatments, $x_{e}$, versus surface concentrations ranging from $4.4 \times 10^{18}$ to $1.2 \times 10^{19}$ atoms $/ \mathrm{cc}$ at $1250^{\circ}$, $1200^{\circ}$ and $1150^{\circ} \mathrm{C}$, respectively, where

Table 1 Surface Concentration of Antimony after Drive-in Diffusion

\begin{tabular}{|c|c|c|c|c|c|}
\hline \multirow{2}{*}{$\begin{array}{l}\text { Predeposi- } \\
\text { tion run }\end{array}$} & \multirow{2}{*}{$\begin{array}{l}\text { Doping level } \\
\text { boron in substrate } \\
\text { (atoms/cc) }\end{array}$} & \multirow{2}{*}{$\begin{array}{l}\text { Sheet } \\
\text { resistivity } \\
\text { (ohm/口) }\end{array}$} & \multicolumn{2}{|c|}{ Surface concentration } & \multirow{2}{*}{$\begin{array}{l}\text { Diffusion } \\
\text { length } \\
(\mu)\end{array}$} \\
\hline & & & $\begin{array}{l}\text { Differential } \\
\text { conductance } \\
\text { (atoms/cc) }\end{array}$ & $\begin{array}{c}\text { Plasma } \\
\text { resonance } \\
\text { (atoms/cc) } \\
\end{array}$ & \\
\hline$\# 1$ & $4.4 \times 10^{14}$ & 21 & $1.3 \times 10^{19}$ & $1.3 \times 10^{19}$ & 6.7 \\
\hline$\# 2$ & $4.4 \times 10^{14}$ & 27 & $9.8 \times 10^{18}$ & $6.6 \times 10^{18}$ & 6.5 \\
\hline$\# 3$ & $4.4 \times 10^{14}$ & 38 & $6.8 \times 10^{18}$ & $5.4 \times 10^{18}$ & 5.7 \\
\hline$\# 1$ & $3.4 \times 10^{15}$ & 28 & $9.2 \times 10^{18}$ & $6.4 \times 10^{18}$ & 6.3 \\
\hline$\# 2$ & $3.4 \times 10^{15}$ & 32 & $8.5 \times 10^{18}$ & $5.1 \times 10^{18}$ & 5.8 \\
\hline$\# 3$ & $3.4 \times 10^{15}$ & 55 & $4.8 \times 10^{18}$ & $3.9 \times 10^{18}$ & 5.6 \\
\hline
\end{tabular}


Table 2 Surface Concentration of Antimony in Substrate During Drive-in Diffusion at $1230^{\circ} \mathrm{C}$ for $12 \mathrm{hrs}$

(background doping level of boron in sugstrate is $4.4 \times 10^{14} \mathrm{~B}$ atoms $/ \mathrm{cc}$ )

\begin{tabular}{l|c|c|c|c}
\hline \hline & $\begin{array}{c}\text { Sheet } \\
\text { resisti- } \\
\text { vity } \\
(\text { ohm/口) }\end{array}$ & $\begin{array}{c}\text { Surface } \\
\text { concent- } \\
\text { ration } \\
\text { (atoms/ } \\
\text { cc) }\end{array}$ & $\begin{array}{c}\text { Reso- } \\
\text { nance } \\
\text { peak } \\
(\mu)\end{array}$ & $\begin{array}{c}\text { Diffusion } \\
\text { length }\end{array}$ \\
\hline $\begin{array}{l}\text { before } \\
\text { drive-in }\end{array}$ & 39 & $2.0 \times 10^{19}$ & 10.7 & 2.8 \\
$\begin{array}{l}\text { after } \\
\text { drive-in }\end{array}$ & 27 & $3.7 \times 10^{18}$ & 22.0 & 9.1 \\
\hline
\end{tabular}

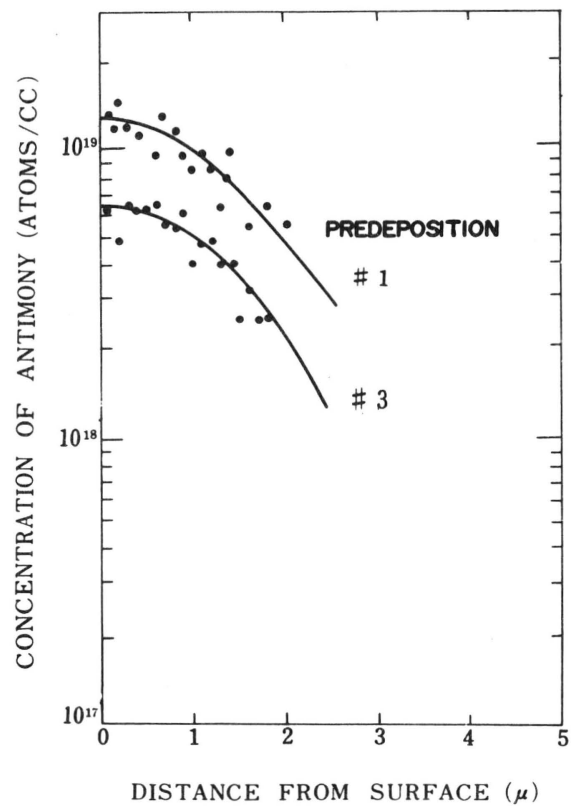

Fig. 2 Some impurity profiles after drive-in diffusion of antimony into substrates at $1250^{\circ} \mathrm{C}$ for $7 \mathrm{hrs}$. Background doping level is $4.4 \times 10^{14} \mathrm{~B}$ atoms/cc.

the background doping level of boron in epitaxial layers is $5.5 \times 10^{16}$ atoms/cc. Fig. 6 is the diffusion length $x_{e}$ from "buried" layers with surface concentration of $6.0 \times 10^{18}$ atoms/cc at $1255^{\circ}$, $1210^{\circ}$ and $1168^{\circ} \mathrm{C}$ versus diffusion time, which includes both heat treatment time and epitaxial time.

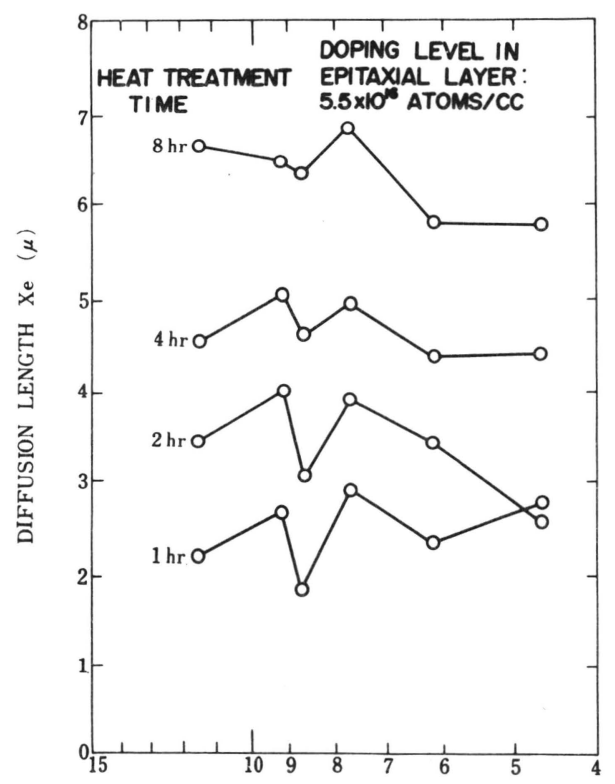

SURFACE CONCENTRATION Ns $\times 10^{18}($ ATOMS $/ C C)$

Fig. 3 Diffusion length $\mathrm{x}_{\mathrm{e}}$ versus surface concentration after heat treatment at $1250^{\circ} \mathrm{C}$

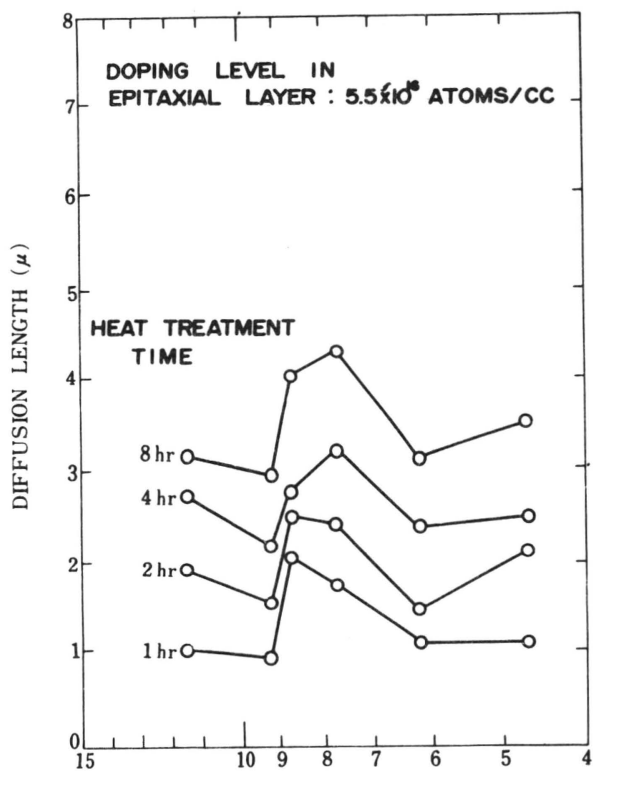

SURFACE CONCENTRATION Ns $\times 10^{18}($ ATOMS/CC)

Fig. 4 Diffusion length $\mathrm{x}_{\mathrm{e}}$ versus surface concentration after heat treatment at $1200^{\circ} \mathrm{C}$ 


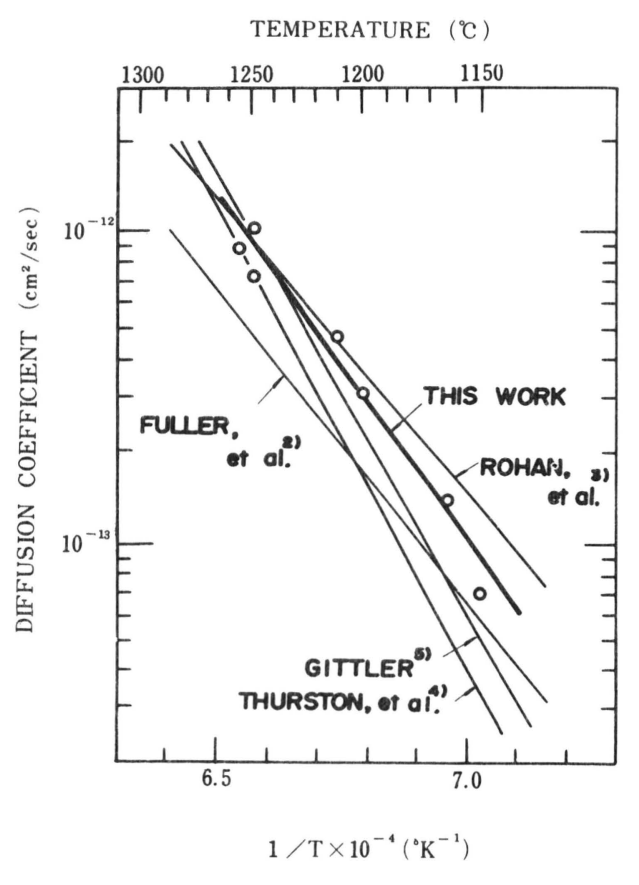

Fig. 8 Diffusion coefficients of antimony in silicon

as a function of temperature from the results of Fig. $3 \sim$ Fig. 5, assuming that the impurity profile is the complementary error function from a finite layer. From this figure, diffusion coefficients can be expressed as a function of absolute temperature $\mathrm{T}$ as follows,

$$
\mathrm{D}=3.62 \times 10^{2} \exp (-101400 / \mathrm{RT})(6)
$$

where $\mathrm{R}$ is the gas constant, $1.986 \mathrm{cal}$ /mole.degree, and the activation energy of diffusion of antimony in silicon, $\Delta \mathrm{H}$, is $101400 \mathrm{cal} / \mathrm{mole}$.

\section{Discussion}

In order to evaluate the diffusion of antimony from "buried" layer, it is very important to know whether the impurity profile is error function or gaussian function, because the impurity profile of antimony in epitaxial layers after heat treatment is greatly influenced by surface concentration in substrates; that is, if the impurity profile just below substrate surface after the drive-in diffusion is complementary error function, the calculation and the determination of diffusion coefficients would be very troublesome. Fortunately, as seen in Fig. 2., the impurity profile in the substrate is like a gaussian function near the interface rather than the complementary error function. One of the causes of this decrease of surface concentrations during the drive-in diffusion is the oxidation of substrate and outdiffusion of antimony. The oxide thickness is about $7800 \mathrm{~A}$ at $1230^{\circ} \mathrm{C}$ for $12 \mathrm{hrs}$ in oxygen so that some amount of antimony may be removed in spite of the pile up tendency due to the distribution coefficient of antimony at silicon-silicon dioxide interface of $1.2^{8}$ ). The profile in the substrate far from the interface is the complementary error function rather than the gaussian function; that is, the use of surface concentration after predeposition of antimony for the calculation of diffusion length in the substrate gives a satisfactory result as shown in Fig. 7.

On the other hand, the impurity profile in the epitaxial layers can not exactly be identified as the complementary error function from Fig. 7, because of the larger experimental errors in differential conductance measurement in the epitaxial layer than in the substrate. However, as far as the diffusion length in the epitaxial layer after heat treatment is concerned, the complementary error function diffusion from a finite layer is believed to be valid unless the heat treatment is carried out for long time compared with the drive-in diffusion time. The facts that the impurity concentration near the interface in substrate is almost constant as seen in Fig. 2 and there is no possibility of losses of antimony during the heat treatment after epitaxial growth support 
this assumption.

The cause of difference of surface concentration dependent of background doping levels in Table 1 is not clear, but it may come from the different surface conditions before or during predeposition such as the thickness of damaged layer and oxide layer of substrates.

The slight decrease of diffusion length with the decrease of surface concentration, which is seen in Fig. $3 \sim$ Fig. 5, can be explained by the equation (5); this means that no significant increase of diffusion coefficient with the increase of surface concentration from $4.4 \times 10^{18}$ to $1.2 \times 10^{19}$ atoms/cc was observed.

The diffusion coefficients obtained in this diffusion process from "buried" layers are somewhat higher than either Fuller's ${ }^{1)}$ or Gittler's $\mathrm{s}^{5)}$ or Thurston' $\mathrm{s}^{4)}$ in the temperature range $1250^{\circ} \sim 1150^{\circ} \mathrm{C}$, but lower than Rohan's ${ }^{3)}$. The main cause of these deviations is errors in determination of surface concentrations and impurity profiles, particularly, the rapid decrease of surface concentration during diffusion should be taken account of.

Although there was a report ${ }^{9}$ ) representing existence of interfacial region with a high diffusion coefficient between epitaxial layer and substrate, no such an interfacial region has been observed in diffusions of antimony from "buried" layers in agreement with impurity profile of antimony in the growing silicon epitaxial growth ${ }^{10}$ ).

\section{Conclusion}

All these results allow us to draw some conclusions as follows,

1) Surface concentrations of antimony during the drive-in diffusion decrease rapidly with diffusion time.

2) Impurity profile of antimony in the substrate near interface is not the complementary error function, but diffusion length far from the interface can be calculated from diffusion coefficients and surface concentrations after the predeposition using the complementary error function.

3) Impurity profile of antimony in the epitaxial layer is the complementary error function from a finite layer.

4) Diffusion coefficient of antimony in silicon can be expressed by $\mathrm{D}=3.63 \times 10^{2}$ $\exp (-101400 / R T) \mathrm{cm}^{2} / \mathrm{sec}$.

5) No significant dependence of diffusion coefficient on concentration was observed in the concentration range of antimony $4.4 \times 10^{18 \sim 1.2 \times 10^{19}}$ atoms/cc in silicon.

6) No interfacial region with a high diffusion coefficient between epitaxial layer and substrate is observed in silicon epitaxial wafer with "buried" layers.

\section{Acknowledgement}

The authors wish to express their appreciation to $\mathrm{H}$. Osafune, Y. Matukura and M. Aoki for encouragement and discussion, to T. Kasukawa for measurements of surface concentrations, and to Y. Nakayama for assistance to this work.

\section{Literature:}

1) W. C. Dunlap, Jr., H. V. Bohm, H. P. Mohon, Jr., Phys. Rev. 96, 822 (1954).

2) C. S. Fuller, J. A. Ditzenberger, J. Appl. Phys. 27, 544 (1956).

3) J. J. Rohan, N. E. Pickering, J. Kennedy, J. Electrochem. Soc. 106, 705 (1959).

4) M. O. Thurston, J. Tsai, AD 274 969 (1962).

5) F. L. Gittler, Electrochem. Soc. Mtg., Extended Abstracts No. 94, May (1967).

6) J. C. Irvin, Bell. Syst. Tech. J. 41, 387 (1962).

7) E. E. Gardner, W. Kappallo, C. R. Gordon, Appl. Phys. Letters 9, 432 (1966).

8) B. E. Deal, A. S. Grove, E. H. Snow, C. T. Sah, J. Electrochem. Soc. 112, 309 (1965). 
9) D. Kahng, G. O. Thomas, R. C. Manz, J. Electrochem. Soc. 109, 1106 (1962).
10) A. S. Grove, A. Roder, C. T. Sah, J. Appl. Phys., 36, 802 (1965).

\title{
The Preparation of $\mathrm{Co}_{x} \mathrm{Fe}_{3-x} \mathrm{O}_{4}$ Thin Films by Epitaxial Method
}

\author{
Yukinobu KUMASHIRO \\ Department of Applied Electrochemistry, Faculty of Engineering, \\ Tokyo Institute of Technology, Ookayama, Meguro-ku, Tokyo
}

Received Oct. 11, 1967

Single crystal films of $\mathrm{Co}_{\mathrm{x}} \mathrm{Fe}_{3-\mathrm{x}} \mathrm{O}_{4}$ as well as polycrystals are prepared epitaxially by decomposing the metal bromides with vapor upon $\mathrm{MgO}$ single crystal with (100) plane and upon non-crystalline $\mathrm{SiO}_{2}$ as the substrates. The films are of spinel structure by X-ray diffraction analysis. The films grown upon $\mathrm{SiO}_{2}$ substrate are consist of randomly distributed macro single crystal particle (the particle sizes are about $5 \mu$ ) with (111) plane, but on the whole they show polycrystal pattern by Reflection Type Electron Diffraction method. The films, which its crystal axis are always parallel to that of $\mathrm{MgO}$ substrate, and have four-fold symmetry, are epitaxially grown on the (100) surface of $\mathrm{MgO}$ crystal by deposition upon it. Magnetic crystal anisotropy constant $\mathrm{K}_{1}$ was calculated as $1.3 \times 10^{6} \mathrm{erg} / \mathrm{cm}^{3}$ by torque measurement.

\section{Introduction}

The relationship between the magnetic and the semiconducting properties of $\mathrm{Co}_{\mathrm{x}} \mathrm{Fe}_{3-\mathrm{x}} \mathrm{O}_{4}(0<\mathrm{x} \leqq 1)$ sintered polycrystals, has been ever reported ${ }^{1,2), 3)}$ as follows;

As sintering polycrystals have, for example, boundary, impurity, porosity, etc. so single samples are desirable rather than polycrystals to analysis physical properties. It is rather difficult, however, to procude the single crystal of ferrites by conventional method - Flux method,
Bridgman method, Vernuilli method, etc.. On the other hand, single crystal thin films are obtained comparatively easily by epitaxial growth as it is seen in $\mathrm{Si}$ and Ge.

From the standpoint of application, ferrite thin films have important part in switching device, miniature electric circuit device etc..

Therefore, it seems to be an interesting problem that we investigate the ferrite thin films on both sides of its fundamental physical properties and of its ap- 